\title{
ON THE BOUNDS OF MULTIVALENTLY STARLIKENESS AND CONVEXITY
}

\author{
SHIGEYOSHI OWA \\ Department of Mathematics, Kinki University \\ Higashi-Osaka, Osaka 577, Japan \\ and \\ MAMORU NUNOKAWA \\ Department of Mathematics, Gunma University \\ Aramaki, Maebashi, Gunma 371, Japan
}

(Received December 22, 1987)

ABSTRACT, The object of the present paper is to prove some interesting results for the bounds of starlikeness and convexity of certain multivalent functions.

KEY WORDS AND PHRASES, p-valently starlike, p-valently convex, typically real.

1980 AMS SUBJECT CLASSIFICATION CODES. 30C45, 30A32.

I. INTRODUCTION.

Let $A(p)$ denote the class of functions of the form

$$
f(z)=z^{p}+\sum_{n=p+1}^{\infty} a_{n} z^{n} \quad(p \in N=\{1,2,3, \cdots\})
$$

which are analytic in the unit disk $U=\{z:|z|<1\}$. A function $f(z)$ in the class $A(1)$ is said to be a member of the class $P$ if and only if it satisfies

$$
\operatorname{Re}\left\{f^{\prime}(z)\right\}>0 \quad(z \varepsilon U) .
$$


It is well known that if $f(z)$ belongs to the class $P$, then $f(z)$ is univalent in $U$ (cf. [1], [2]).

Many results for this class were obtained, but the radius of starlikeness for the class $P$ is not known.

Lewandowski [3] has proved that if $f(z)$ belongs to the class $P$, then $f(z)$ is starlike in $|z|<4 \sqrt{2}-5 \div 0.6568$. This result has been improved in ([4], [5]) as follows:

If $f(z)$ belongs to the class $P$, then $f(z)$ is univalently starlike in $|z|<\rho$, where $\rho$ is the smallest positive root of the equation

$$
\log \frac{1}{1-r^{2}}+\sin ^{-1}-\frac{2 r}{1+r^{2}}=\pi
$$

and $0.901<\rho<0.902$.

2. PRELIMINARIES.

DEFINITION I. Let $f(z) \in A(p)$ and

$$
\operatorname{Re}\left\{\frac{z f^{\prime}(z)}{f(z)}\right\}>0 \quad(|z|<r \leqq 1) .
$$

Then we shall call a function $f(z)$ p-valently starlike in $|z|<r$. We denote by $S(p)$ the subclass of $A(p)$ consisting of functions which are p-valently starlike in $U$.

DEFINITION 2, Let $f(z) \varepsilon A(p)$ and

$$
\operatorname{Re}\left\{1+\frac{z f^{\prime \prime}(z)}{f^{\prime}(z)}\right\}>0 \quad(|z|<r \leq 1) .
$$

Then we shall call a function $f(z)$ p-valently convex in $|z|<r$. Also we denote by $C(p)$ the subclass of $A(p)$ consisting of all p-valently convex functions in the unit disk $U$.

LEMMA I, (Ruscheweyh [6]) Let $f(z)$ be in the class $P$, and assume that $f^{\prime}(z)$ is typically real in $U$. Then $f(z)$ is univalently starlike in the unit disk $U$.

LEMMA 2. (Nunokawa [7]) Let $f(z)$ be in the class $A(p)$, and suppose that 


$$
\operatorname{Re}\left\{\frac{z f^{(p)}(z)}{f^{(p-1)}(z)}\right\}>0 \quad(|z|<r \leq 1) .
$$

Then we have

$$
\operatorname{Re}\left\{\frac{z f^{(k)}(z)}{f^{(k-1)}(z)}\right\}>0 \quad(|z|<r)
$$

or $f^{(p-k)}(z) \in S(k)$ in $|z|<r$ for $k=1,2,3, \cdots, p$.

LEMMA 3. (Nunokawa [7]) Let $f(z)$ be in the class $A(p)$, and suppose

$$
p+\operatorname{Re}\left\{\frac{z f^{(p+1)}(z)}{f^{(p)}(z)}\right\}>0 \quad(|z|<r \leq 1) .
$$

Then we have

$$
k+\operatorname{Re}\left\{\frac{\mathrm{zf}^{(k+1)}(z)}{\mathrm{f}^{(k)}(z)}\right\}>0 \quad(|z|<r)
$$

for $k=0,1,2, \cdots, p-1$. This shows that $f(z) \in C(p)$ and $f(z) \in S(p)$.

\section{BOUNDS OF STARLIKENESS AND CONVEXITY.}

We begin with the statement and the proof of the following result.

THEOREM I. Let the function $f(z)$ belong to the class $A(p)$ with $p \geqq 2,\left(f^{(p-1)}(z) / p !\right) \in P$, and $\left(f^{(p)}(z) / p !\right)$ be typically real in $U$. Then $f(z)$ is p-valently convex in $U$ and p-valently starlike in $U$.

PROOF, Let $F(z)=f^{(p-1)}(z) / p !$. Then it is clear that $F(0)=0$ and $F^{\prime}(0)=1$. Also, since $F(z) \in F, \operatorname{Re}\left\{F^{\prime}(z)\right\}>0(z \in U)$, and $F^{\prime}(z)$ is typically real in $U$. An application of Lemma 1 to the function $F(z)$ gives that

$$
\operatorname{Re}\left\{\frac{z F^{\prime}(z)}{F(z)}\right\}=\operatorname{Re}\left\{\frac{z f^{(p)}(z)}{f^{(p-I)}(z)}\right\}>0 \quad(z \in U U)
$$

Therefore, with the aid of Lemma 2, we have

$$
\operatorname{Re}\left\{\frac{z f^{\prime \prime}(z)}{f^{\prime}(z)}\right\}>0 \quad(z \in U)
$$


and

$$
\operatorname{Re}\left\{\frac{z f^{\prime}(z)}{f(z)}\right\}>0 \quad(z \in \in U) .
$$

The above inequalities imply that $f(z) \varepsilon C(p)$ and $f(z) \varepsilon S(p)$, respectively. Thus we complete the proof of Theorem 1 .

Next, we prove

THEOREM 2. Let the function $f(z)$ belong to the class $A(p)$, and $\left(f^{(p-1)}(z) / p !\right) \varepsilon P$. Then $f(z)$ is $p$-valently convex in $|z|<r(p)$,

where

$$
r(p)=\frac{\sqrt{p^{2}+1}-1}{p} .
$$

PROOF, Defining the function $F(z)$ as in the proof of Theorem 1 , that is, $F(z)=\left(f^{(p-1)}(z) / p !\right)$, we have $F(0)=0, F^{\prime}(0)=1$ and $\operatorname{Re}\left\{F^{\prime}(z)\right\}>0(z \in U)$. Then it is well known that

$$
\left.\left|\frac{z F^{\prime \prime}(z)}{F^{\prime}(z)}\right|=\left|\frac{z f^{(p+1)}(z)}{f^{(p)}(z)}\right| \leq \frac{2|z|}{1-|z|^{2}} \quad \text { (z } \varepsilon U U\right) \text {. }
$$

Thus, it follows from the above that

$$
p+\operatorname{Re}\left\{\frac{z f^{(p+1)}(z)}{f^{(p)}(z)}\right\} \geq p-\frac{2|z|}{1-|z|^{2}}>0
$$

for $|z|<r(p)$. Making use of Lemma 3 leads to

$$
\operatorname{Re}\left\{1+\frac{z f^{\prime \prime}(z)}{f^{\prime}(z)}\right\}>0
$$

for $|z|<r(p)$ which completes the proof of Theorem 2 .

REMARK. We can not find out an extremal function of Theorem 2.

Applying the same method as in the proof of [5], and using Lemma 2, we have the following result.

THEOREM 3. Let the function $f(z)$ belong to the class $A(p)$, and $\left(f^{(p-1)}(z) / p l\right) \varepsilon P$. Then $f(z)$ is p-valently starlike in $|z|<\rho_{1}$, where $\rho_{1}$ is the smallest positive root of the equation 


$$
\log \frac{1}{1-r^{2}}+\sin ^{-1} \frac{2 r}{1+r^{2}}=\pi
$$

and $0.901<\rho_{1}<0.902$.

Further, spending the same manner as in the proof of ([8], [9]), and using Lemma 2, we get the followimg theorem.

THEOREM 4, Let the function $f(z)$ belong to the class $A(p)$, and

$$
\left|f^{(p)}(z)-p !\right|<p ! \quad(z \in U) .
$$

Then $f(z)$ is p-valently starlike in $|z|<\rho_{2}$, where $\rho_{2}$ is the smallest positive root of the equation

$$
\log \left(9-4 r^{2}+4 r^{3}-r^{4}\right)-\log 9\left(1-r^{2}\right)+\sin ^{-1} r=\pi
$$

and $0.933<\rho_{2}<0.934$.

Letting $\mathrm{p}=1$ in Theorem 4, we have

COROLLARY. Let the function $f(z)$ belong to the class $A(1)$, and

$$
\left|f^{\prime}(z)-1\right|<1 \quad(z \in U) .
$$

Then $f(z)$ is univalently starlike in $|z|<\rho_{2}$, where $\rho_{2}$ is given as in Theorem 4.

REMARK. The above corollary is an improvement of the result in [10, Theorem 6].

Finally, we derive

THEOREM 5. Let the function $f(z)$ belong to the class $A(p)$, and

$$
\left|f^{(p+1)}(z)\right| \leq k|z|^{k-1} p ! \quad(z \in U),
$$

where $k$ is a positive real number. Then $f(z)$ is p-valent in $U$.

PROOF. From the assumption of Theorem 5, we see that

$$
\left|f^{(p)}(z)-p !\right|=\left|\int_{0}^{z} f^{(p+1)}(t) d t\right|
$$




$$
\begin{aligned}
& \leq \int_{0}^{|z|}\left|f^{(p+1)}(t)\right||d t| \\
& \leq \int_{0}^{|z|} k|t|^{k-1}|d t|=|z|^{k} p !<p !
\end{aligned}
$$

for $z \in U$. This implies that $\operatorname{Re}\left\{f^{(p)}(z)\right\}>0(z \varepsilon U)$. By applying Ozaki's theorem [11] to the function $f(z)$, we conclude that $f(z)$ is p-valent in $U$.

\section{REFERENCES}

1. NOSHIRO, K. On the theory of schlicht functions, J. Fac. Sci. Hokkaido Univ. (1) 2(1934/1935), 129 - 155 .

2. WARSCHAWSKI, S. On the higher derivatives at the boundary in conformal mappings, Trans. Amer. Math. Soc. 38(1935), 310 - 340.

3. LEWANDOWSKI, Z. L'identité de certaines classes de fonctions univalentes, Ann. Univ. Mariae Curie-Sklodowska, Sect. A, 14(1960), $19-46$.

4. MACGREGOR, T. H. A class of univalent functions, Proc. Amer. Math. Soc. $15(1964), 311-317$.

5. NUNOKAWA, M. On the starlike boundary of univalent functions, Sūgaku 31(1979), 255 - 256, (Japanese).

6. RUSCHEWEYH, S. Coefficient conditions for starlike functions, Glasgow Math. J. 29(1987), 141 - 142 .

7. NUNOKAWA, M. On the theory of multivalent functions, Tsukuba J. Math. $\underline{11}(1987), 37-50$.

8. FUKUI, S., OWA, S., OGAWA, S., and NUNOKAWA, M. A note on a class of analytic functions satisfying $\operatorname{Re}\left\{f^{\prime}(z)\right\}>\alpha$, Bull. Fac. Edu. Wakayama Univ. Nat. Sci. 36(1987), $13-17$.

9. NUNOKAWA, M., FUKUI, S., OWA, S., SAITOH, H., and SEKINE, T. On the starlike boundary of univalent functions, Math. Japon., to appear.

10. NUNOKAWA, M. On the theory of univalent functions, Sci. Rep. Fac. Educ. Gunma Univ. 20(1971), 1 - 9.

11. OZAKI, S. On the theory of multivalent functions, Sci. Rep. Tokyo Bunrika Daigaku 2(1935), 167 - 188. 


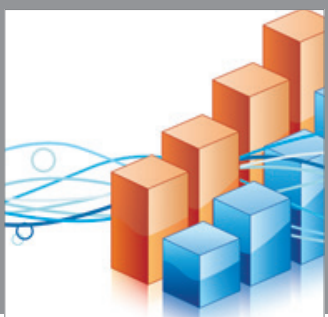

Advances in

Operations Research

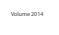

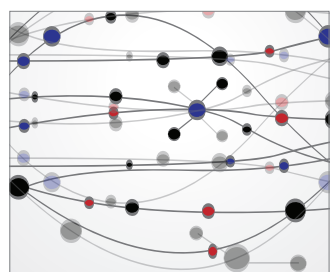

\section{The Scientific} World Journal
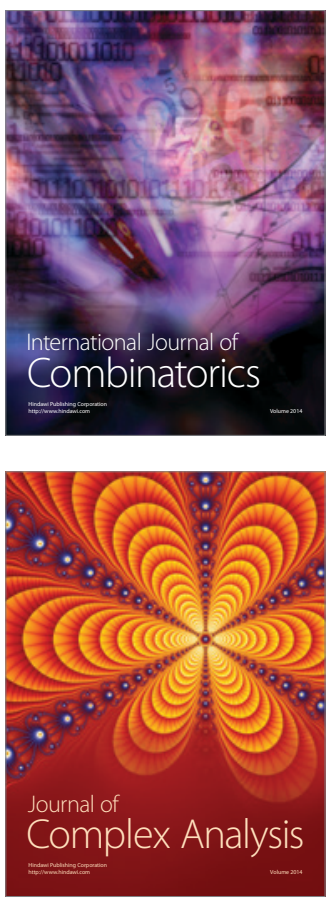

International Journal of

Mathematics and

Mathematical

Sciences
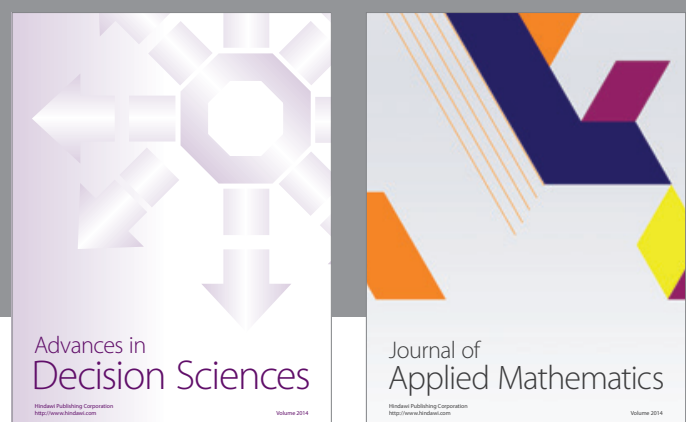

Journal of

Applied Mathematics
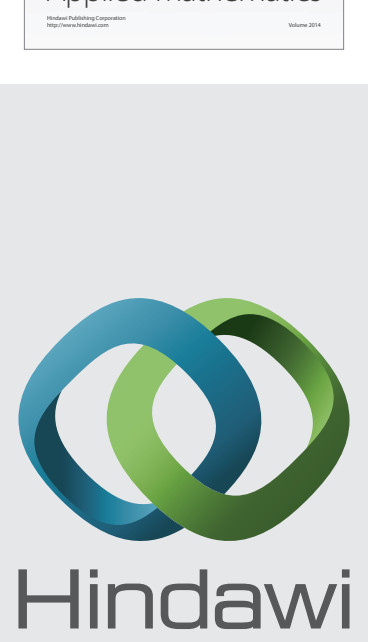

Submit your manuscripts at http://www.hindawi.com
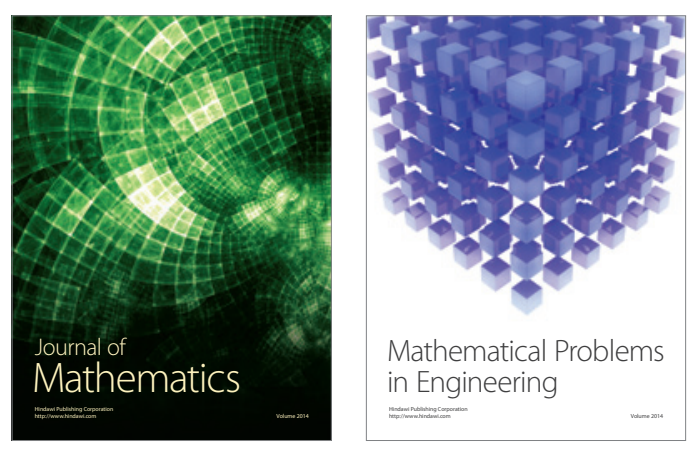

Mathematical Problems in Engineering
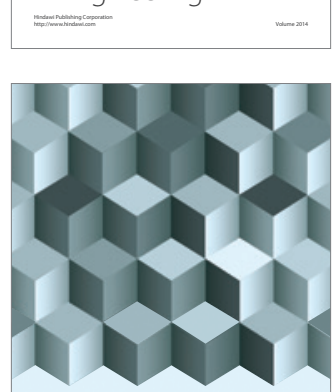

Journal of

Function Spaces
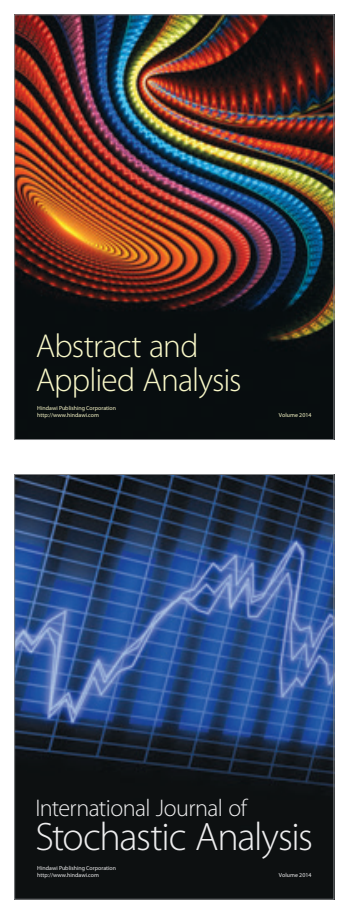

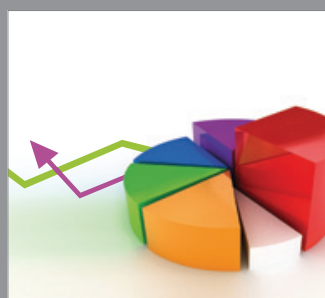

ournal of

Probability and Statistics

Promensencen
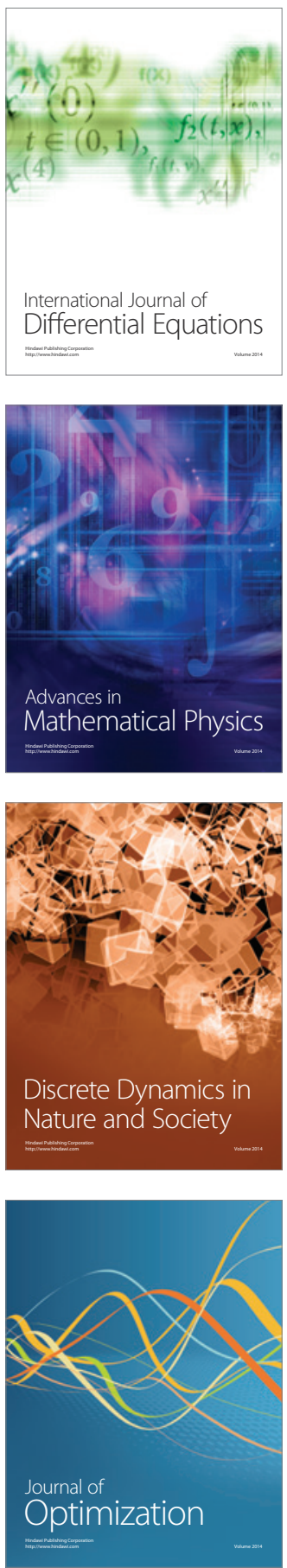